\title{
Laboratory evaluation of noise reducing asphalt mixtures
}

\author{
Viktoras Vorobjovas ${ }^{\mathrm{a}}$, Tadas Andriejauskas ${ }^{\mathrm{a}}$, Aleksandras Jagniatinskis ${ }^{\mathrm{b}}$ \\ ${ }^{a}$ Road Research Institute, Vilnius Gediminas Technical University, Linkmenu str. 28, LT-08217 Vilnius, Lithuania \\ ${ }^{b}$ Laboratory of Acoustics, Scientific Institute of Thermal Insulation, Vilnius Gediminas Technical University, \\ Linkmenu str. 28, LT-08217 Vilnius, Lithuania
}

\begin{abstract}
The article gives a study of factors influencing noise emissions from the interaction of the tyre and road surface. Theoretical principles of asphalt pavements with optimised noise reducing characteristics are identified in the paper. In accordance with the experience of implementation and exploitation of noise reducing asphalt mixtures in other European countries, two concepts of noise reducing pavements were prepared for Lithuanian conditions. Laboratory tests were performed for these conceptual asphalt mixtures and other asphalt mixtures with promising noise reducing characteristics. Physical and mechanical characteristics of different noise reducing asphalt mixtures were determined, compared and evaluated. With regards to the research results, article concludes with recommendations of noise reducing asphalt mixtures suitability for implementation in Lithuanian road network.
\end{abstract}

Keywords: tyre/road noise; noice reducing asphalt pavements; laboratory tests.

\section{Introduction}

Environmental noise is described as a different kind of unwanted and harmful sound, which spreads in terms of time and geographical coverage. Because of harmful effects on human health and living quality, noise is considered to be one of the major environmental protection problems. It is stated, that $20 \%$ of European Union (EU) inhabitants are exposed to noise, which is higher than $65 \mathrm{dBA}$ [1] - noise level of discomfort is considered at 55-65 dBA [2]. Higher noise levels than permissible negatively affects people - disturbance of usual activities (e.g., sleep, rest, work, learning, communication) and damage to human body (state of mind, hearing, nervous system, cardiovascular system) [3]. Noise is also harmful to wildlife population and orientation in the environment [4].

Economically negative noise impact is described as increased costs related to real estate depreciation and reduction of work efficiency due to health effects or nuisance [5]. Socio-economic costs are related to early deaths or diseases. Noise generation is associated with many different people activities, but the major part of noise is generated by road, rail and air transport. It is calculated that annual socio-economic costs in EU because of roads and railways noise are about $40 \mathrm{mln}$. EUR. $90 \%$ of these are because of light and heavy vehicle traffic (approx. $0.4 \%$ of EU GDP including health care costs). Forecasts show that the costs related to traffic noise will increase approximately to 20 billion EUR until 2050 [6].

Vehicle noise consists of power unit noise (engine, powertrain, exhaust etc.) [7], tyre/road noise and aerodynamic noise. Power unit noise dominates when the vehicle accelerates or decelerates and drives at low speed (under $60 \mathrm{~km} / \mathrm{h}$ ). Aerodynamic noise starts to dominate when the vehicle drives at high speed (over $120 \mathrm{~km} / \mathrm{h}$ ). Rapid automotive technology advance in recent years significantly reduced vehicle noise but still when the vehicle drives faster than $60 \mathrm{~km} / \mathrm{h}$, tyre $/ \mathrm{road}$ noise becomes a dominant source of vehicle noise [8].

There are different noise abatement measures such as noise barriers, traffic management, bypasses, special road design solutions, traffic and speed restrictions, land use planning, and low noise pavements [9]. Environmentally friendly (in terms of low noise) road infrastructure is certainly one of the priorities for welfare of society.

Despite the sufficient development of Lithuanian road network, it was planned when the traffic volumes were not so high as nowadays and the major objective was to connect residential locations and cross them. Due to the rapid increase of traffic volumes, in EU and in Lithuania environmental protection, especially noise reduction plays a bigger role. In Lithuania there is a lot of unused potential to reduce tyre and road surface contact noise. Low noise and noise reducing pavements are being

Corresponding author: Tadas Andriejauskas. E-mail address: tadas.andriejauskas@vgtu.lt

http://dx.doi.org/10.3846/enviro.2014.178

(C) 2014 The Authors. Published by VGTU Press. This is an open-access article distributed under the terms of the Creative Commons Attribution License, which permits unrestricted use, distribution, and reproduction in any medium, provided the original author and source are credited. 
developed and implemented in warmer climate countries. According to the EU experience, in Lithuanian climate conditions, it is possible to create and develop asphalt mixes and asphalt layers which could reduce tyre/road noise by $2-4 \mathrm{dBA}$.

\section{Tyre/road noise}

Tyre/road noise generates because of the rolling tyre and road surface interaction. Road surface has a huge impact on noise emission, because noise generation and propagation is very dependent on the road surface characteristics. Tyre/road noise and its level could be described by noise generation mechanisms [10]:

- noise due to tyre vibrations;

- noise due to tyre aerodynamics;

- noise amplification/reduction effect.

Noise due to tyre vibrations achieves highest amplitudes when the frequency is low (under $1000 \mathrm{~Hz}$ ) and noise spectral composition is dependent on driving speed and road surface texture. Noise due to tyre aerodynamics is also dependent on driving speed and the highest amplitudes is when the frequency is high (over $1000 \mathrm{~Hz}$ ) [11]. Air which is sucked in between the tyre and road surface could be "locked" either in tyre thread or in surface macrotexture cavities. Tyre/road noise is a result of a different noise generating mechanisms [10-12] including "sucked in" air, impact vibrations, stick-snap vibrations, adhesion vibrations. The intensity of each mechanism could be stronger or weaker dependently on the pavement properties. Noise emission also could be amplified or reduced by few other mechanisms such as cavity resonance, pipe resonance, Helmholtz resonance and horn effect [11]. Tyre/road noise could be affected by many different factors related with the road surface, tyre properties, driving behaviour, environment conditions, driving speed etc.

Road surface characteristics:

- Road surface texture and formation. Increased texture wavelengths from $0.5 \mathrm{~mm}$ to $10 \mathrm{~mm}$ when the frequency is high can reduce noise generation, but increased texture wavelengths from $10 \mathrm{~mm}$ to $500 \mathrm{~mm}$ when the frequency is low can increase noise generation. It is also very important if the texture is "negative" or "positive" [13]. "Positive" texture is formed from particles, which protrude above road surface plane, while "negative" texture is characterizes not the projection of particles, but spaces between particles, which top forms flat surface plane. Depending on the aggregate particle size, "positive" texture generates considerably higher noise, while "negative" texture reduces noise [10], [13].

- Aggregate properties. Higher noise is proportional to the aggregate particle size. Noise can be reduced by using smaller maximum aggregate particle size, sharp particles, homogenous particle size and shape (ideally cubic shape). Particles also must be ranged close to each other that spaces between them be as small as possible ("negative" texture) [13], [14].

- Road surface air voids content. Higher air void content leads to better noise absorption. Noise absorption is also dependent on the air permeability and pore connection. Porous road surfaces also play an important role in reducing noise by absorbing above road surface propagating noise [15], [16].

- Pavement stiffness. Tyre vibrations can be reduced by reducing road pavement mechanical impedance what also reduce tyre thread block and road surface interaction forces, which are transmitted to the tyre [10].

- Pavement colour. Dark surfaces better absorb solar radiation and are a bit warmer than bright surfaces. Black colour pavement could be $10^{\circ} \mathrm{C}$ warmer than grey colour pavement, what leads to $1 \mathrm{dBA}$ lower noise emissions [14], [17].

- Pavement age and deterioration. Road pavement acoustical behaviour shouldn't be assessed only in the primary pavement exploitation phase, but also has to maintain good acoustical properties all the life cycle [15], [18].

- Friction and microtexture.

- Joints on bridges and concrete pavements.

- Road roughness.

Tyre characteristics:

- Number of tyres. Additional tyres (for heavy vehicles) lead to bigger noise emissions.

- Tyre dimensions. Increased tyre width leads to bigger noise emissions [19].

- Tyre internal structure. The reduction of tyre reinforcement belt stiffness increases tyre/road noise, decrease of tyre carcass stiffness also leads to the lower noise emissions.

- Tyre inequality. Inequality between the tyres leads to higher noise levels for the low frequency sound waves.

- Rubber hardness. Difference between the tyre/road noise levels due to rubber hardness could be up to 5-8 dBA [14].

- Tread structure.

- Tyre age and wear [17].

- Tyre type.

- Re-treaded tyres.

- Studded tyres. Comparing tyre/road noise levels between studded tyres and usual tyres, the difference of noise levels could be up to $8 \mathrm{dBA}$ [10], [11].

Environment parameters:

- Temperature. Noise level changes 0.05-0.1 dBA for each temperature degree [18].

- Moisture.

- Water. When the vehicle drives on wet pavement at $60 \mathrm{~km} / \mathrm{h}$ speed, noise increases from $2 \mathrm{dBA}$ to $6 \mathrm{dBA}$ [14].

- Wind. Aerodynamic noise due to air turbulence near the vehicle and near the wheels could increase total vehicle noise.

- Dust. 
- Winter maintenance.

Parameters controlled by driver:

- Driving speed. Due to speed differences (from $30 \mathrm{~km} / \mathrm{h}$ to $130 \mathrm{~km} / \mathrm{h}$ ), noise emission varies up to $25 \mathrm{dBA}$ [10], [11], [14].

- Tangential forces and acceleration. Dependently on driving and braking forces (longitudinal sliding) noise emission could increase up to $12 \mathrm{dBA}[10]$.

- Tyre load and pressure. Doubling wheel load, noise emission increases 1-2 dBA [14].

\section{Noise reducing asphalt mixtures}

\subsection{Theoretical principles of noise reducing pavements}

Noise reducing pavements according to their structure can be divided into three types [11]: dense, semi-porous and porous pavements. Dense structure surface noise reduction properties are associated with the smoother surface texture, porous structure surface - with noise absorption (tyre/road noise and noise propagation above the surface). Semi-porous surface noise reduction characteristics are associated with the reduction of tyre vibrations, sound absorption and air pumping.

The most significant road surface characteristics causing tyre/road noise are road surface texture and air void content (porosity). Modification of these characteristics is the most effective and commonly used method to reduce tyre/road noise [20], [21].

Development of road pavements with optimized road surface texture reduces tyre vibrations, resulting from the surface roughness, and ensures adequate air propagation conditions at tyre and road contact. Optimized surface texture could be achieved by using smaller maximum aggregate particle size and compacting that the spaces between particles would be as small as possible - "negative" texture. Most effective road surface texture optimization techniques are: to increase road surface texture in $2-8 \mathrm{~mm}$ wavelength range and reduce texture in $20-250 \mathrm{~mm}$ wavelength range [10].

Porous pavements with high air void content eliminates noise, generated due to air pumping and resonance mechanisms, and ensures good noise, floating above the surface, absorption [15]. Smooth surface for porous pavements is as much important as for dense pavements so it is useful to find balance between porosity and texture smoothness. Traffic noise from porous pavements reflects indirectly and get inside the porous layer where the noise is reduced. When porosity is higher than $10 \%$, road pavement becomes acoustically absorbing, but good noise reduction properties can be achieved when the porosity is as high as $20 \%$ [10].

"Soft" pavement creation where surface texture is flexible is also one of the ways to reduce tyre/road noise. Because of higher pavement strength (comparing with tyre), during contact, tyre deforms and vibrates. Reducing road pavement stiffness could reduce tyre deformations and vibrations. However, asphalt pavement with reduced stiffness still has to maintain sufficient pavement stability [22].

\subsection{Use of noise reducing asphalt pavements in foreign countries}

Implementation of noise reducing pavements is effective and inexpensive way to reduce tyre/road noise. Current technologies could reduce tyre/road noise by $2 \mathrm{dBA}$, but using modern and innovative technologies could help to achieve a much higher noise reducing effect.

Stone and mastic asphalt (SMA) [23] mixture is one of perspective choices to reduce noise after 4-5 years of exploitation. Optimised SMA mixtures are with small maximum aggregate particle size $(5-6 \mathrm{~mm})$, spaces between particles are $2-4 \mathrm{~mm}$ wide and aggregate particles are from $100 \%$ crushed stone particles, with cubic shape and high wearing resistance. Polymer modified bitumen binder or crushed rubber granules additives for binder are often used. In Germany SMA mixtures helps to reduce tyre/road noise approximately by $4-5 \mathrm{dBA}$ [24-25].

Porous asphalt pavements are one of the most popular and commonly used noise reducing pavements in practice [10]. Porous pavements with good acoustical properties are with $8 \mathrm{~mm}$ diameter maximum aggregate particle size, 20-23\% of air void content and $40 \mathrm{~mm}$ layer thickness [26-27]. Clogging by dust or dirt and insufficient resistance to cold climate are the main problems of porous pavements. In Germany and UK performed research showed that the warranty period of porous pavements is up to 5 years, where initial noise reduction is $8 \mathrm{dBA}$, but each year decreasing by $0.5-1.0 \mathrm{dBA}$ [20].

Double layer porous asphalt pavement is more resistant to clogging than single layer porous asphalt. Top layer is composed from smaller fraction aggregate while the bottom layer from larger fraction aggregate. Noise dissipates in the porous layers while the dirt couldn't get into air voids in the deeper layers in porous pavement [10-12]. Double layer porous asphalt is popular in Sweden, Denmark and in Netherlands where noise reduction by using of this type pavements is about 5-9 dBA. Commonly used maximum aggregate particle size in top layer is $5 \mathrm{~mm}$ or $8 \mathrm{~mm}$, in bottom layer $-16 \mathrm{~mm}$ or $22 \mathrm{~mm}$. Thickness of two layers varies from $55 \mathrm{~mm}$ to $90 \mathrm{~mm}$ [22].

Thin asphalt layer technology is effective because the implementation of this type pavement is fast and simple - minimal traffic interruption [20], [21]. Thin layer is an alternative between single or double layer porous asphalt acoustical properties and traditional asphalt durability [13]. Noise is reduced by optimised surface macrotexture and asphalt mixtures are strengthened by adding elastomers or synthetic fibres. Thin layers are widely used in Denmark and UK where noise reduction by using thin layers is about 3-4 dBA [20], [21], [28]. 
Poroelastic asphalt is one of the most perspective noise reducing asphalt pavement types where the wearing course is made by using high content of rubber granules. Rubber content in asphalt mixture is about $20 \%$, where rubber granules are bonded with binder and small aggregate size particles what leads to porous structure. Air void content varies from $20 \%$ to $40 \%$ (of asphalt volume). Noise reducing effect is very high - from $5 \mathrm{dBA}$ to $15 \mathrm{dBA}$, but the pavement stability is insufficient [10], [29], [30].

Rubber asphalt is dense asphalt pavement, implemented by using asphalt mixture with high content of crushed rubber granules $-15 \%$ of total mixture mass. Research in Sweden showed that rubber asphalt technologies are effective when the texture is open graded with $11 \mathrm{~mm}$ size of maximum aggregate fraction, $20 \%$ of binder mixed with $10 \%$ of rubber granules, air void content about $15 \%$, layer thickness $-40 \mathrm{~mm}$. Effect of noise reduction - 3-7 dBA [10, 22].

\subsection{Low noise pavement concept for Lithuanian road network}

According to the analysed theoretical principles of noise reducing pavements and implementation experience in EU countries, Vilnius Gediminas Technical University (VGTU) Faculty of Environmental Engineering (AIF) Road Research Institute (KTI) have created and developed two conceptual noise reducing stone and mastic asphalt (SMA TM) mixture concepts for Lithuanian climate conditions. Concepts are based on smooth road surface texture creation using smaller size aggregate but retaining sufficient stability and durability properties. It is also important to form "negative" road surface texture which could be created by using homogenous fraction and cubic shape aggregate particles. EU experience shows that SMA TM asphalt mixtures could reduce tyre/road noise emission approximately by $4 \mathrm{dBA}$.

For noise reducing asphalt mixtures, especially thin layers, polymer modified bitumen (PMB) binder is being used. Using PMB binder for noise reducing asphalt pavements, increase asphalt pavement resistance to cracking, binder drainage and durability.

Depending on heavy transport percentage in traffic, SMA TM asphalt mixtures for Lithuanian conditions are suggested to be SMA 5 TM and SMA 8 TM. When dominates light vehicles in traffic it is appropriate to use 5 mm diameter maximum aggregate particle size, but when dominates heavy transport - it is recommended to use $8 \mathrm{~mm}$ diameter maximum aggregate particle size. Requirement for these asphalt mixtures are shown in Table 1.

Table 1. Composition of conceptual noise reducing asphalt mixtures SMA 5 TM and SMA 8 TM

\begin{tabular}{lcc}
\hline & SMA 5 TM & SMA 8 TM \\
\hline Aggregate grading & & \\
Passing aggregate: & $100 \%$ & $90-100 \%$ \\
fraction $>8 \mathrm{~mm}$ & $85-100 \%$ & $20-30 \%$ \\
fraction $>5 \mathrm{~mm}$ & $20-30 \%$ & $15-20 \%$ \\
fraction $>2 \mathrm{~mm}$ & $6-9 \%$ & $5-8 \%$ \\
fraction $<0.063 \mathrm{~mm}$ & & \\
\hline Binder & PMB $45 / 85-55$ & PB $45 / 85-55$ \\
type & $\geq 7.0 \%$ & $\geq 6.5 \%$ \\
content & Cellulose fibre & Cellulose fibre \\
\hline Stabilization additives & $>0.15$ & $>0.3$ \\
content & $135 \pm 5{ }^{\circ} \mathrm{C}$ & $135 \pm 5{ }^{\circ} \mathrm{C}$ \\
\hline Compaction temperature & $7-9 \%$ & $8-10 \%$ \\
\hline Air void content & & \\
\hline
\end{tabular}

\section{Laboratory testing}

\subsection{Research object and methodology}

According to the requirements for conceptual noise reducing asphalt mixtures SMA 5 TM and SMA 8 TM, these asphalt mixtures were designed and produced in VGTU AIF KTI Road Research Laboratory. In order to compare physical and mechanical characteristics of conceptual noise reducing asphalt mixtures, in laboratory were also designed and produced traditional asphalt mixtures SMA $8 \mathrm{~S}$ and SMA $11 \mathrm{~S}$. For a better comparison of conceptual noise reducing asphalt mixtures and asphalt mixtures that are being used in market, laboratory tests was also performed for JSC "Eurovia Lietuva" asphalt product Viaphone (Asphalt mixtures with three different quantities of binder were delivered by manufacturer).

Conceptual and traditional asphalt mixtures were produced by using bitumen binder PMB 45/80-55. Granite stone were used as an aggregate. To improve bonding between aggregate and binder, $0.2 \%$ (of binder content) of adhesive additive Iterlene IN 400/L were added to the asphalt mixtures. There was also added $0.4 \%$ (of asphalt mixture mass) of cellulose fibre - binder stabilizing additive.

Asphalt mixtures SMA $8 \mathrm{~S}$ and SMA $11 \mathrm{~S}$ were produced according to the LST EN 13108-5 standard and normative document "Description of technical requirement for asphalt mixtures" (TRA ASFALTAS 08) requirements.

All asphalt mixtures were produced by using three different quantities of binder. The following physical and mechanical properties were determined:

- air void content, according to LST EN 12697-8;

- Marshall stability and flow, according to LST EN 12697-34; 
- indirect tensile strength ratio ITSR, according to LST EN 12697-12;

- indirect tensile strength, according to LST EN 12697-23.

\subsection{Research results}

Laboratory testing results of asphalt mixtures air void content are shown in Figure 1. Higher air void content leads to better noise absorption. Designed air void content of conceptual asphalt mixtures SMA 5 TM and SMA 8 TM (respectively 7-9\% and $8-10 \%)$ is higher than traditional asphalt mixtures SMA $8 \mathrm{~S}$ and SMA $11 \mathrm{~S}(2-3 \%)$. Research has shown that noise reducing asphalt mixture Viaphone air void content (3.6-5.9\%) is also higher than traditional asphalt mixtures SMA $8 \mathrm{~S}$ and SMA $11 \mathrm{~S}$. According to required air void content and later according to physical and mechanical properties, asphalt mixtures with optimal and close to optimal content of binder were identified:

- SMA 5 TM optimal binder content $6.7 \%$, close to optimal $-6.4 \%$;

- SMA 8 TM optimal binder content $6.3 \%$, close to optimal $-6.6 \%$;

- SMA 8 S optimal binder content $6.7 \%$, close to optimal - $7.0 \%$;

- SMA $11 \mathrm{~S}$ optimal binder content $6.3 \%$, close to optimal $6.6 \%$;

- Viaphone optimal binder content I var. (according to JSC "Eurovia Lietuva"), close to optimal - II var.

According to the research results, Viaphone asphalt mixture has higher stability by Marshall - it varies from $13.0 \mathrm{kN}$ to $13.5 \mathrm{kN}$. Conceptual asphalt mixture SMA 8 TM has the lowest Marshall stability - it varies from $3.7 \mathrm{kN}$ to $3.9 \mathrm{kN}$ (Fig. 2). Stability by Marshall results of other tested asphalt mixtures are similar and varies from $6.0 \mathrm{kN}$ to $9.0 \mathrm{kN}$, average $7.05 \mathrm{kN}$.

Considering flow by Marshall aspect of asphalt mixtures, test results showed that all asphalt mixtures are similar and the Marshall flow varies from $2.4 \mathrm{~mm}$ to $5.1 \mathrm{~mm}$, average $-3.33 \mathrm{~mm}$ (Fig. 3). SMA $11 \mathrm{~S}$ asphalt mixture's Marshall flow is a bit higher than other mixtures - from $4.6 \mathrm{~mm}$ to $5.1 \mathrm{~mm}$, average $-4.9 \mathrm{~mm}$.

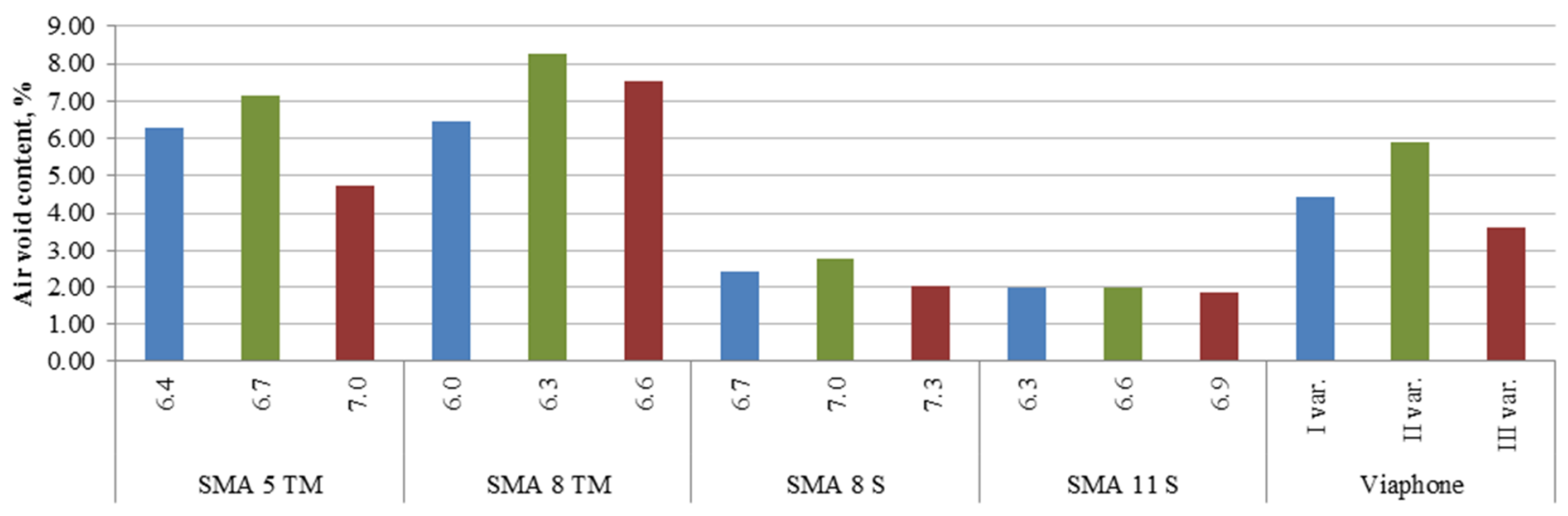

Fig. 1. Air void content testing results

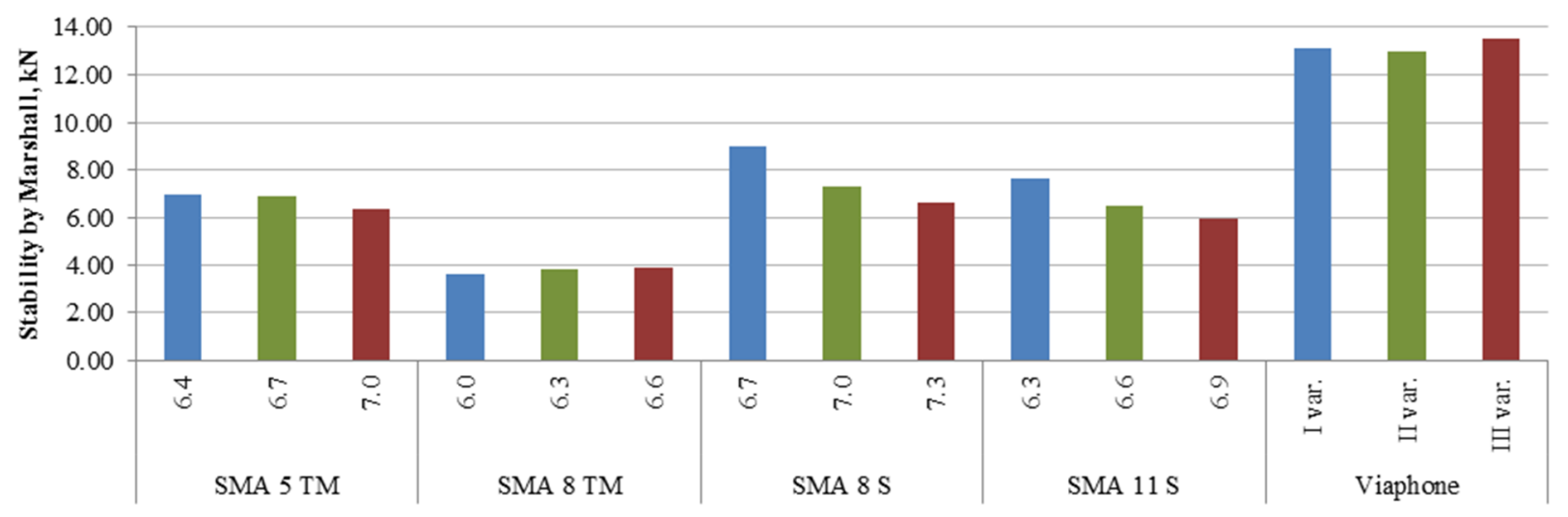

Fig. 2. Stability by Marshall testing results 


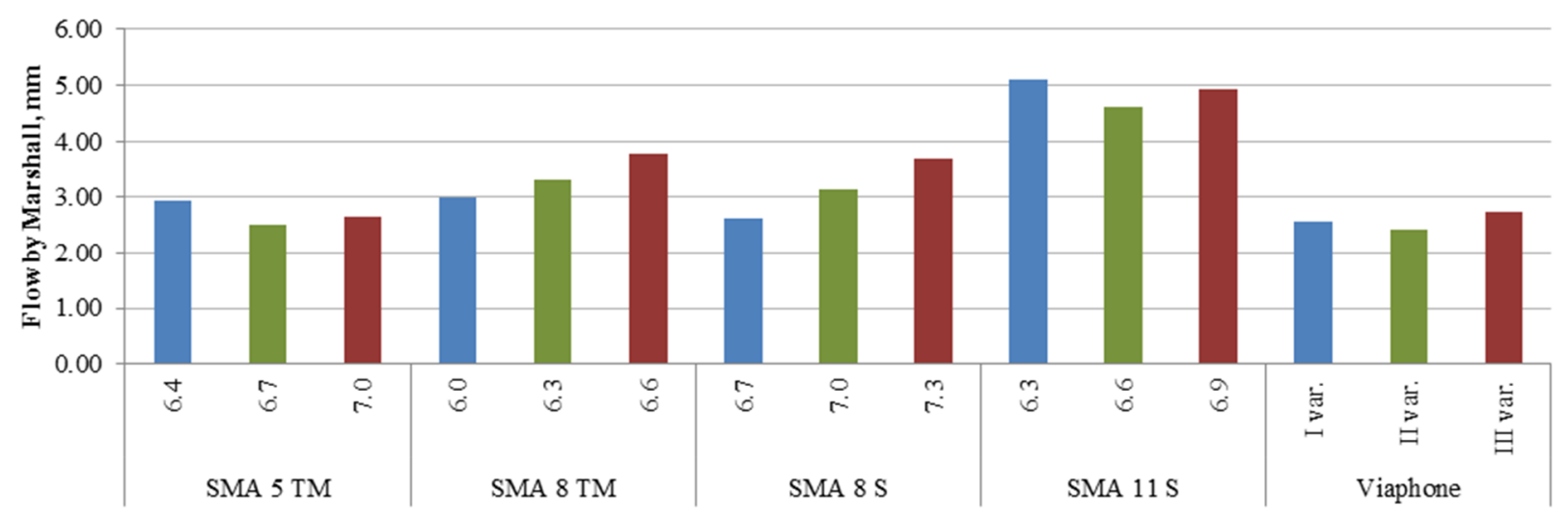

Fig. 3. Flow by Marshall testing results

Indirect tensile strength ratio for all tested asphalt mixtures varies from $79.6 \%$ to $117.4 \%$ (Fig. 4). This ratio for conceptual and used in market noise reducing asphalt mixtures varies from $79.6 \%$ to $90.2 \%$. Indirect tensile strength ratio of traditional asphalt mixtures is $21 \%$ higher than noise reducing asphalt mixtures.

According to indirect tensile strength testing results, highest indirect tensile strength were determined for Viaphone asphalt mixtures (0.001559-0.001643 GPa) (Fig. 5). Conceptual asphalt mixture SMA 8 TM has lowest indirect tensile strengths from all tested asphalt mixtures - it varies from $0.000694 \mathrm{GPa}$ to $0.000737 \mathrm{GPa}$, average $-0.000716 \mathrm{GPa}$. Indirect tensile strength for other asphalt mixtures (SMA 5 TM, SMA $8 \mathrm{~S}$ and SMA $11 \mathrm{~S}$ ) are similar and varies from $0.000812 \mathrm{GPa}$ to $0.001174 \mathrm{GPa}$, average $-0.001009 \mathrm{GPa}$.

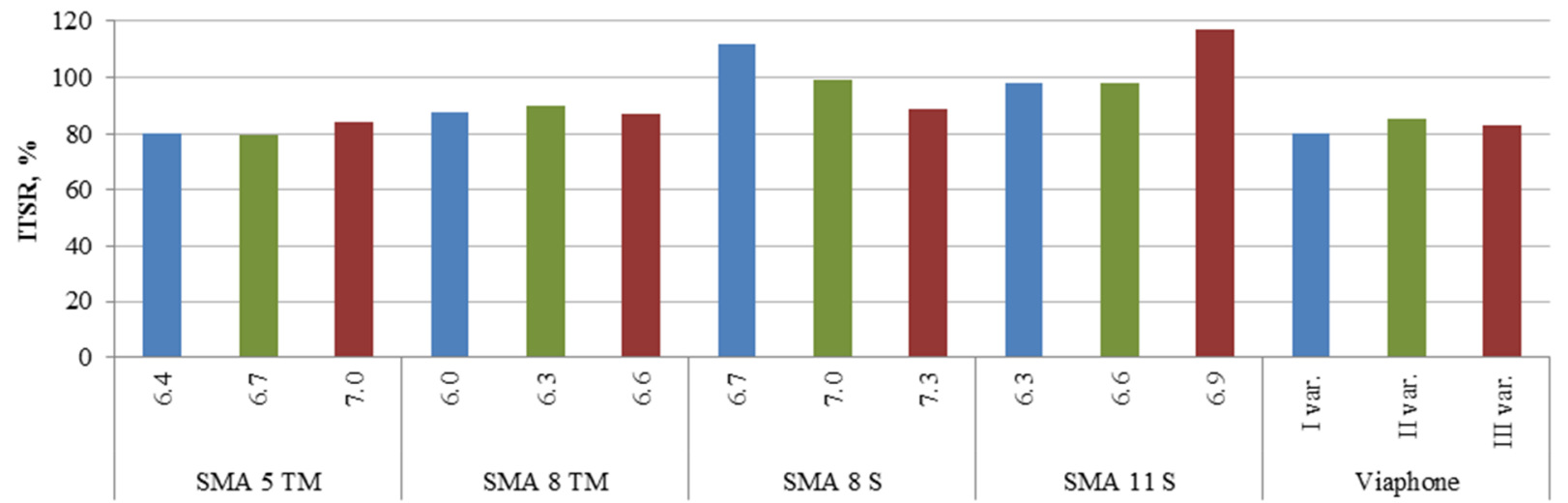

Fig. 4. Indirect tensile strength ratio testing results

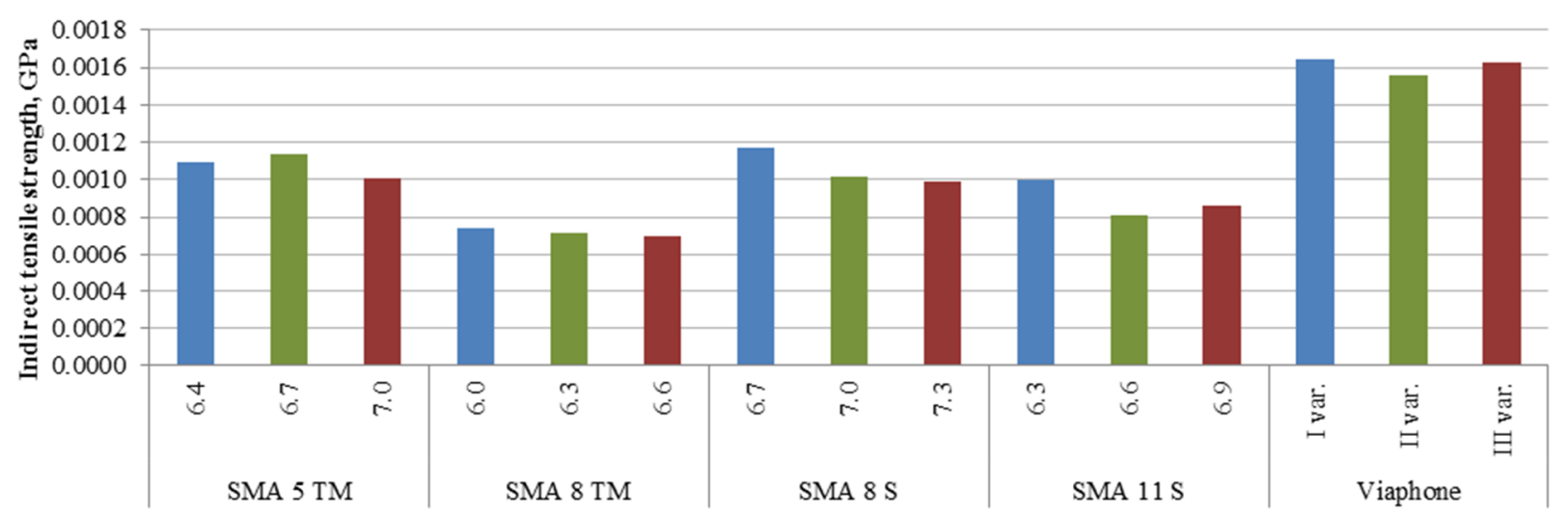

Fig. 5. Indirect tensile strength testing results

\subsection{Future research}

Creation and development of noise reducing asphalt pavement concepts will be continued in future by assessing these asphalt mixtures suitability for Lithuanian climate conditions and determining noise reduction characteristics and economic efficiency. Road surface macrotexture and noise absorption are major indicators which assess noise reduction characteristics 
and developing noise reducing asphalt mixture composition and technology, applied research should cover road surface macrotexture measurement and acoustic testing methodologies. For that purpose it is planned to perform further research and laboratory testing of conceptual and traditional asphalt mixtures SMA 5 TM, SMA 8 TM, SMA 8 S, SMA $11 \mathrm{~S}$ by assessing their noise reduction characteristics (road surface mean texture depth (MTD) and sound absorption) and stability (durability). Stability and durability will be assessed by determining asphalt mixture specimens' particle losses (according to LST EN 12697-17) and indirect tensile strength rates after heating/cooling cycles.

\section{Conclusions}

1. Main asphalt pavement noise reduction techniques: road surface texture optimization, increase of pavement air void content and pavement stiffness reduction. The most effective way is to combine texture optimization and porosity increase.

2. Asphalt mixtures for tyre/road noise reduction should not have only good noise reducing characteristics but also should have good stability, durability and maintain good acoustical properties during all lifecycle.

3. Porous asphalt pavements is an effective mean to reduce tyre/road noise, however this kind of pavements rapidly clogs and are sensitive to cold climate. Due to specific climate conditions in Lithuania, cold periods in winter time with many freeze-thaw cycles, porous pavement usage should be tested by field trials.

4. Noise reducing stone mastic asphalt (SMA TM) mixtures, according to their physical and mechanical properties, are more suitable for Lithuanian climate conditions. Depending on heavy vehicle percentage in whole traffic flow, it is recommended to use SMA $5 \mathrm{TM}$ and SMA $8 \mathrm{TM}$ asphalt mixtures, where maximum aggregate particle size is respectively $5 \mathrm{~mm}$ and $8 \mathrm{~mm}$.

5. Laboratory testing results of physical and mechanical properties of asphalt pavements showed that conceptual noise reducing asphalt mixtures SMA 5 TM and SMA 8 TM could be used in practice, but before there should be performed additional tests which could help to evaluate these conceptual asphalt mixtures noise reducing characteristics and resistance cold climate conditions.

\section{References}

[1] Commission of the European Communities. 1996. Future noise policy - European Commission Green Paper. COM(96) 540. Brussels, $40 \mathrm{p}$

[2] Jaecker-Cueppers, M. 2002. Quieter Roads and Rails in Europe: a Vision for 2030. CALM Workshop with Stakeholders.

[3] Chmieliauskienè, Ž. 2005. Automagistraliu transporto keliamo triukšmo poveikio sveikatai ir gyvenimo kokybei valdymas Lietuvoje. [Highway noise impact on health and living quality management in Lithuania]. Magistro baigiamasis darbas [Master thesis]. Kauno medicinos universitetas, Kaunas, $102 \mathrm{p}$.

[4] Geležinkeliu bendradarbiavimo organizacija OSŽD. 2001. Geležinkeliu transporto keliamo triukšmo poveikio aplinkai vertinimo rekomendacijos [Recommendations for assessing railway noise impact on environment]. Vilnius, $15 \mathrm{p}$.

[5] Miedema, H.; Oudshoorn, C. 2001. Annoyance from transportation noise: relationships with exposure metrics DNL and DENL and their confidence intervals, Environmental Health Perspectives 109(4): 409-416.

[6] European Commission. 2011. Report from the Commission to the European Parliament and the Council: On the implementation of the Environmental Noise Directive in accordance with Article 11 of Directive 2002/49/EC. COM(2011) 321 final. Brussels, 13 p.

[7] Cerrato, G. 2009. Automotive Sound Quality - Powertrain, Road and Wind Noise, Sound \& vibration 43(4): 16-24. ISSN 1541-0161.

[8] PIARC Technical Committee 14 Environment. 2002. Environmental Impact of Existing Pavements. 136 p. ISBN 2-84060-121-4

[9] Bendtsen, H.; Hasz-Singh, H.; Kirkeby, W.; Gretarsson, B.; Figge, H.; O’Malley, V.; Besnard, F.; Scriabine, P.; Minchelsen, L.; Fryd, J.; Giannopoulou, E.; Strommer, K.; Hagstromm, L.; Thurzo, G.; Liebert, T.; Alberts, W. 2010. Noise management and abatement. CEDR, 108 p.

[10] Sandberg, U.; Ejsmont, J. 2002. Tyre/Road Noise Reference Book. Informex, Harg, SE-59040, Kisa, Sweden. 640 p.

[11] Haider, M.; Bendtsen, H.; Berengier, M.; Nilsson, R.; Nilsson, R. 2008. Guidelines for low-noise road surface maintenance and rejuvenation. SILENCE Project, $50 \mathrm{p}$

[12] Haider, M.; Descornet, G.; Sandberg, U.; Pratico, F.G. 2007. Road traffic noise emission: recent developments and future prospects, in International SIIV Congress, Palermo.

[13] Bendtsen, H. 2008: DRI-DWW Thin Layer Project - Final Report. Danish Road Directorate/Road Institute, DRI report 159.

[14] Kane, M.; Scharnnigg, K.; Conter, M.; Roe, P.; Schwalbe, G. 2009. Report on different parameters influencing skid resistance, rolling resistance and noise emissions. TYROSAFE project, $95 \mathrm{p}$.

[15] Raitanen, N. 2005. Measuring of noise and wearing of quiet surfaces. Doctoral dissertation. Espoo, $105 \mathrm{p}$

[16] Liao, G.; Sakhaeifar, M. S.; Heitzman, M.; West, R.; Waller, B.; Wang, S.; Ding, Y. 2014. The effects of pavement surface characteristics on tire/pavement noise, Applied Acoustics 76: 14-23. http://dx.doi.org/10.1016/j.apacoust.2013.07.012

[17] Anfosso-Ledee, F.; Pichaud, Y. 2007. Temperature effect on tyre-road noise, Applied Acoustics 68: 1-16. http://dx.doi.org/10.1016/j.apacoust.2006.06.001

[18] Ho, K.; Hung, W.; Ng, C.; Lam, Y.; Leung, R.; Kam, E. 2013. The effects of road surface and tyre deterioration on tyre/road noise emission, Applied Acoustics 74: 921-925. http://dx.doi.org/10.1016/j. apacoust.2013.01.010

[19] Kumar, A.; Tandon, A.; Paul, S.; Singla, A.; Kumar, S.; Vijay, P.; Bhangale, U.D. 2011. Influence of Tyre's Dimensional Characteristics on TyrePavement Noise Emission, Physical Review and Research International 1(4): 124-137.

[20] Bendtsen, H.; Andersen, B.; Thomsen, S.N. 2007. “Optimized thin layers for highways - Inter-noise paper 2007”. Report 153, Road Directorate, Danish Road Institute, Hedehusene, Denmark

[21] Sandberg, U.; Kragh, J.; Goubert, L., Bendtsen, H.; Bergier,s A.; Biligiri, K. P.; Karlsson, R.; Nielsen, E.; Olesen, E.; Vansteenkiste, S. 2011 Optimization of thin asphalt layers - state of the art review. $140 \mathrm{p}$.

[22] Sandberg, U. 2008. Review and evaluation of the low-noise road surface programme for low-speed roads in Hong Kong. $113 \mathrm{p}$.

[23] Comité Européen de Normalisation. 2005. prEN 13108-5: Bituminous mixtures - Material specifications - Part 5: Stone mastic asphalt. CEN, Brussels, Belgium

[24] Ripke, O. 2011. Lärmmindernder Splittmastixasphalt. Berichte der Bundesanstalt für Straßenwesen (bast). Bergisch Gladbach. 25 p. ISSN $0943-9323$ 
[25] Schellenberg, M. 2007. Lärmmindernde Asphaltbauweisen. VSVI Berlin-Brandenburg „Lärmmindernde Asphaltbauweisen“. Berlin.

[26] Anfosso-Lédée, F.; Dangl, P. 2006. Sound Propagation above a Porous Road Surface by Boundary Element Method, Road Materials and Pavement Design 7(3): 289-312. http://dx.doi.org/10.1080/14680629.2006.9690039

[27] Morgan, P. A. 2008. IPG Research Report - Innovative mitigation measures for road traffic noise. Report DVS-2008-018, Road and Hydraulic Engineering Division of Rijkswaterstaat. Delft, Netherlands.

[28] Andersen, B.; Bendtsen, H.; Larsen, L. E. 2005. Acoustic performance of low noise road pavements. SILVIA Project Report SILVIA-DTF-DRI-01002-WP4-290605

[29] Sandberg, U.; Goubert, L.; Biligiri, K.P.; Kalman, B. 2010. State of the art regarding poroelasting road surfaces. PERSUADE project, 159 p.

[30] Biligiri, K. P.; Kalman, B.; Samuelsson, A. 2011. Understanding the fundamental material properties of low-noise poroelastic road surfaces, International Journal of Pavement Engineering 14(1): 12-23. http://dx. doi.org/10.1080/10298436.2011.608798 